\title{
Research Workshop 1: Explorations in sound and visual art
}

\author{
Graham Diprose \\ Independent Researcher \& Author \\ 13 Heathfield Drive \\ Redhill, Surrey, RH1 5HL, UK \\ grahamdiprose@gmail.com
}

\author{
Balandino Di Donato \\ University of Leicester \\ University Road, \\ Leicester, LE1 7RH, UK \\ balandino.didonato@leicester.ac.uk
}

\author{
Matthew Tate \\ Royal College of Art \\ Casting House, Deptford Foundry \\ New Cross, London, SE14 6BN, UK \\ matthew.tate@network.rca.ac.uk
}

Zuzanna Rabikowska

London College of Communication

University of the Arts

Elephant \& Castle

London SE1 6SB, UK

z.rabikowska@gmail.com
Ruby Rossini

Image Maker \& Designer

Fresh Britain

1 Alfred Place, Soho,

London WC1E 7EB, UK

rossiniruby@gmail.com

\begin{abstract}
The EVA London Research Workshop is one of the more unique elements of our Conference that we have been keen to develop over many years. Often Postgraduate Students, at Masters or PhD level, or Unaffiliated Artists may feel excluded from prestigious conferences until their research is complete and they can submit a full paper proposal. However apart from their Tutors, Supervisors and Mentors, EVA London provides an almost unique opportunity to submit projects which can be truly described as 'Work in Progress'. With an audience of International Academics and acknowledged experts in a field, the Research Workshop presentations have often lead to very positive interest and support, and sometimes to future collaborations, or returning to EVA London a year later with a completed piece of Research and a successful Full Conference Proposal. In previous years the presentations have been very popular with our delegates and as Chair of the Research Workshops I can think of a number of occasions where an audience question that began "Have you thought of..." has lead to very exciting new lines of discovery. Sadly in 2020 we will miss that particular interaction, however, we have, as always selected an exciting, ground breaking and quite eclectic group of RW delegates. We hope that by publishing their papers here, either grouped together, around themes, or individually published, you will be keen to contact our RW authors to discuss and develop ideas, as if we had all been able to meet up together in July 2020.
\end{abstract}

Digital art. Visual art. Sound and music. Photography. Gender.

\section{INTRODUCTION}

\section{Graham Diprose, Co-Chair EVA London}

Our Research Workshop in the 2020 proceedings falls into two categories. Those who have arranged to have their paper published individually, perhaps as part of a PhD defence or funding bid and those happy to be published as part of a group of short papers, sharing similar themes and areas of research. The whole point of the Research Workshop, like some of best of any art-form, is to question and challenge accepted boundaries, which perhaps some other conferences, might tend to avoid. Our Artists in this 'Explorations in the Visual Arts' may well challenge some reader's preconceptions. I might venture to say that one of the reasons that EVA London remains a thriving and growing event, now over 30 years, has been it's continual ability to refresh and reinvent itself. We now attract more young and unaffiliated artists to EVA London than five or ten years ago, and the Research Workshop is one of a number of ways that this has been achieved.

It is exceptionally rewarding for all of us involved in EVA London to see a 'Work in Progress' one year becoming a successful full conference paper the next. I hope that all the very talented authors of this paper will take note. With a conference called 'Electronic Visualisation in the Arts' almost inevitably the distinction and borders between Visual Art and Visual Technology will be blurred. This first RW combined paper will introduce you to 
five Artists who use clever technology as an everyday tool in order for them to explore, create and communicate their innovative visual ideas.

Rather than individually introducing these papers here, I think that each are well able to speak for themselves. Whether you are an academic with digital arts students, or still studying, or are an unaffiliated artist, we are very keen each year to hear from you, if you might like to join the following year's EVA London Research Workshop

\section{DIGITAL ART AND INTERACTION DESIGN}

\section{Balandino Di Donato,} University of Leicester

\subsection{Introduction}

This short paper presents an ongoing work towards the investigation of interaction modalities between a digital art piece, which can involve any of the senses (vision, hearing, balance, smell, taste, or touch), and the audience. Artworks can include real and virtual elements.

This workshop will explore interaction design strategies in reference to the affordances of the elements of the art piece. With affordances here are referred bodily or cognitive actions evoked by the artwork/instrument. The term 'affordance' was first used by the psychologist Gibson (1966), and its principles lie on the possible action that each object invites based on the characteristics of the objects and the capabilities of the subjects (Gibson 1977, 1979).

As well as the interaction between the audience and the digital art piece, this research aims to investigate how the different component of the artwork interact with each other; thus, the interaction between the different features of the feedback, for example, the interaction of colours as in Albers (2013), or the interaction between different form of feedback (i.e. sound-visuals, sound-haptics, visual-haptic and visual-hapticsound).

In other words, the affordances of the installation as a whole. This workshop will benefit artists and technologists that aim to express their artistic ideas through interactions with the art piece that are "natural" and "embodied" in the context of digital art; natural "as being marked by spontaneity" (Grandhi et al. 2011), and embodied as an extension and incorporation of human skills and abilities within the interaction design of a system (Dourish 2001).

\subsection{Previous work}

This research is informed by previous work by the author. Work focused on Human-Sound Interaction and how we can directly interact with sound upon the affordances of the sound. This work explores the idea of direct and embodied interaction with sound as if it would be a tangible and visible object. I define this as Human-Sound Interaction (HSI).

Di Donato and Bullock (2015) explored ways to interact with sound in a mixed-reality environment where the sound affordances and identity are highlighted through natural interaction with processing parameters (see video link below): In Bullock and Di Donato (2016), it was explored the idea of spatialising sound by considering sound as an object that could be grabbed, moved and thrown away as a physical one, and its spatial position determines spatialisation cues (see video online: https://vimeo.com/174099457).

In Di Donato et al. (forthcoming), sound is visualised and presented as a deformable container whose shape is determined by its associated spectral signature. Sound has interactive possibilities demonstrated by the affordances of the visual projection, the mid-air haptic feedback and the sound itself. With an interaction style analogous to moulding and sculpting, the user is able to boost and attenuate frequency components of the sound by interacting directly with the holographic visualisation of the container projected mid-air using hand gestures. Inspired by the continuous vertical and horizontal movement of a sculptor when making pottery using clay and a rotor wheel, filter-bank parameters are controlled by modelling the sound shape through vertical and horizontal hand movements. Modes of interactions (see Figure 2.1 and video online: https://youtu.be/YEs5CngFXdg).

An informal evaluation of the interaction design and the system reported that cross-modal feedback fosters direct actions over the audio process and facilitate the experience of the morphology of sound. Moreover, this approach enabled challenging and discovering new ways of interacting with sound. We also observed that SoundSculpt has the potential to convey sounds to people with any hearing profile, through compensation with other senses. For instance, aural diverse audiences can experience sound through touch and vision, and thus better appreciate the musician's intentions. 


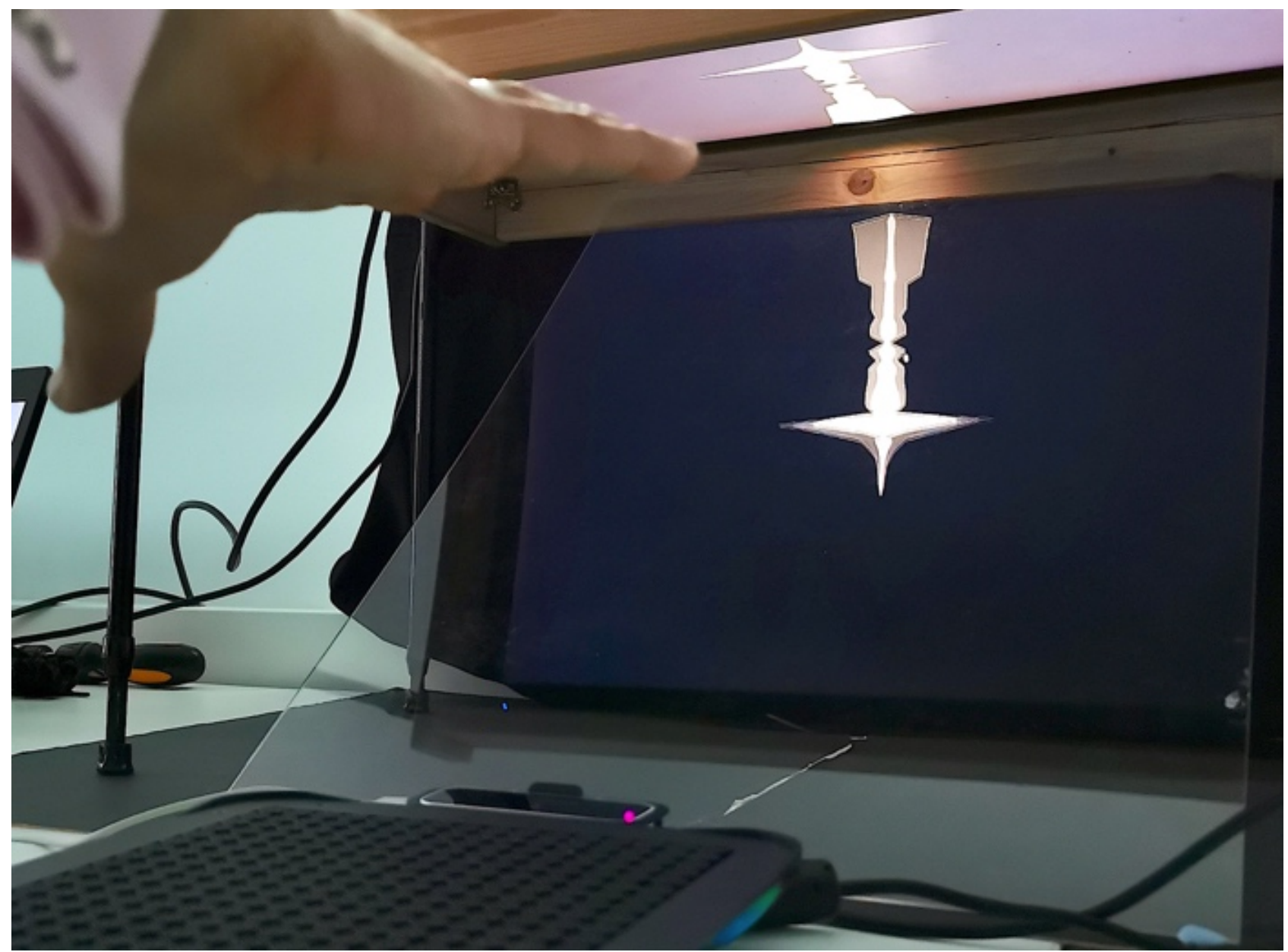

Figure 2.1: The SoundSculpt system.

\subsection{Current and future work}

This first work is leading towards considering not only sound but also extending the concept of direct and embodied interaction to different digital artforms.

I look forward to developing this research further through an ethnographic study. A series of workshop activities and interviews in an interdisciplinary and collaborative environment will be delivered to explore Digital Art and Interaction Design.

The workshop I propose is split into two phases, the first one is led by adopting a co-creation approach using the Co-Navigator (Lindvig 2017), the second one will be a discussion with participants around the themes emerged during the activity. Co-Navigator is an inter-disciplinary problem-solving tool that allows the collaboration on a theme through a multi-dimensional visualisation of the interdisciplinary topography of theme. Co-Navigator addresses the contextual and local circumstances and the unique combinations of participants in a collaborative environment. This tool includes writable tiles and cubes to enable rapid visualisation. The tactile nature of the toolset is to encourage negotiation and collaboration over an eleven steps-process (https://conavigator.org, https://youtu.be//K5qx392h Js).

Semi-structured interviews with Digital Art practitioners and technologists will be conducted to inform the study with more subjective detailed information about the one's interaction design, and how it does affect the creative process.

\subsection{Ethics}

This research is conducted complying with all University of Leicester's Research Ethics Policy, which can be found at the following URL address: https://www2.le.ac.uk/institution/ethics/policy.

\subsection{Acknowledgment}

Future development of this work will be supported by the University of Leicester and the Leicester Institute for Advanced Studies (LIAS). 


\section{THE BOY BITTEN BY A LIZARD}

\section{Matthew Tate, Royal College of Art}

On TV there was an episode of America's Next Top Model where the models posed as modern reinterpretations of classical paintings. One of the paintings chosen was 'The Birth of Venus'. Intrigued, I went on my dad's computer and researched it. What drew me to that painting was how Botticelli had interpreted the myth. I read about the events of Cronos and Zeus's climatic battle, leading up to the exact moment of Venus serenely drifting towards the shore.

My father who needed the computer, was surprised at what I was looking at. Suddenly, he was interested in my interests. We began to spend more time together exploring museums and art galleries together, bonding over our mutual appreciation for the renaissance masters. He saw a chance to expand my artistic education, but under the surface it was a chance for us to bond over a subject we could talk about. Eventually we would go to Italy to see the painting in the Uffizi. He would go on to buy me a poster of the painting for Christmas.

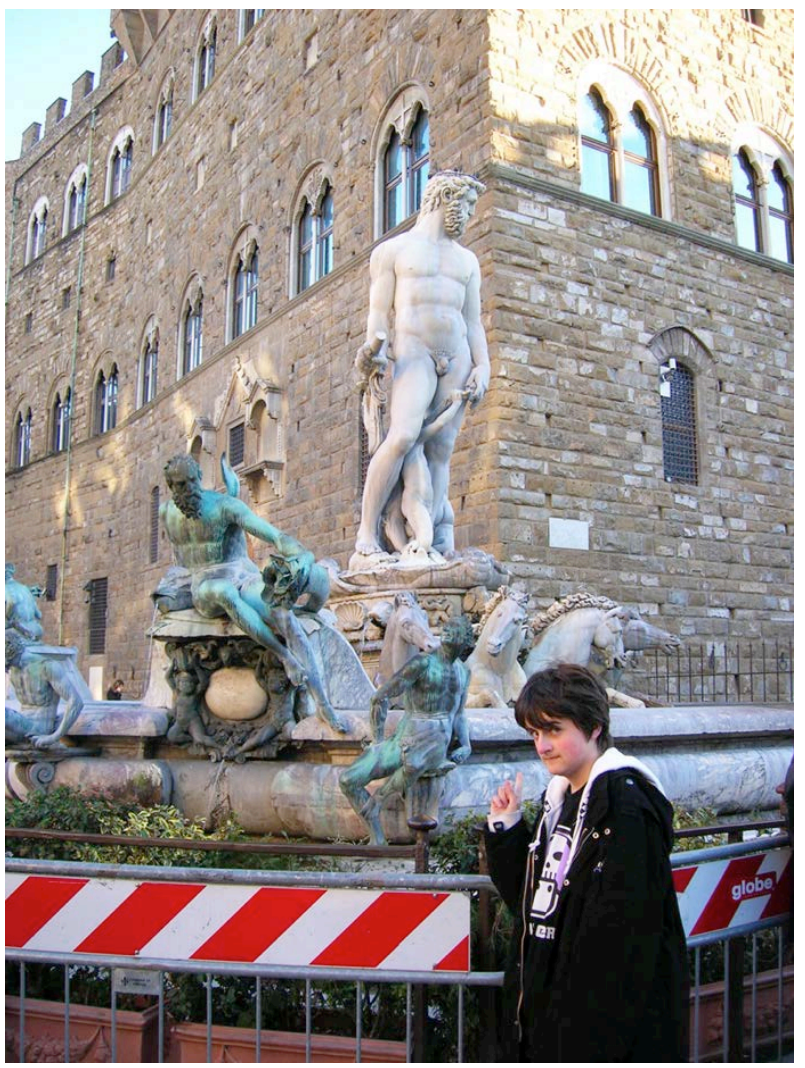

Figure 3.1: Photograph of me next to the Fountain of Neptune outside the Uffizi Gallery Florence. Taken by my Father circa 2005.

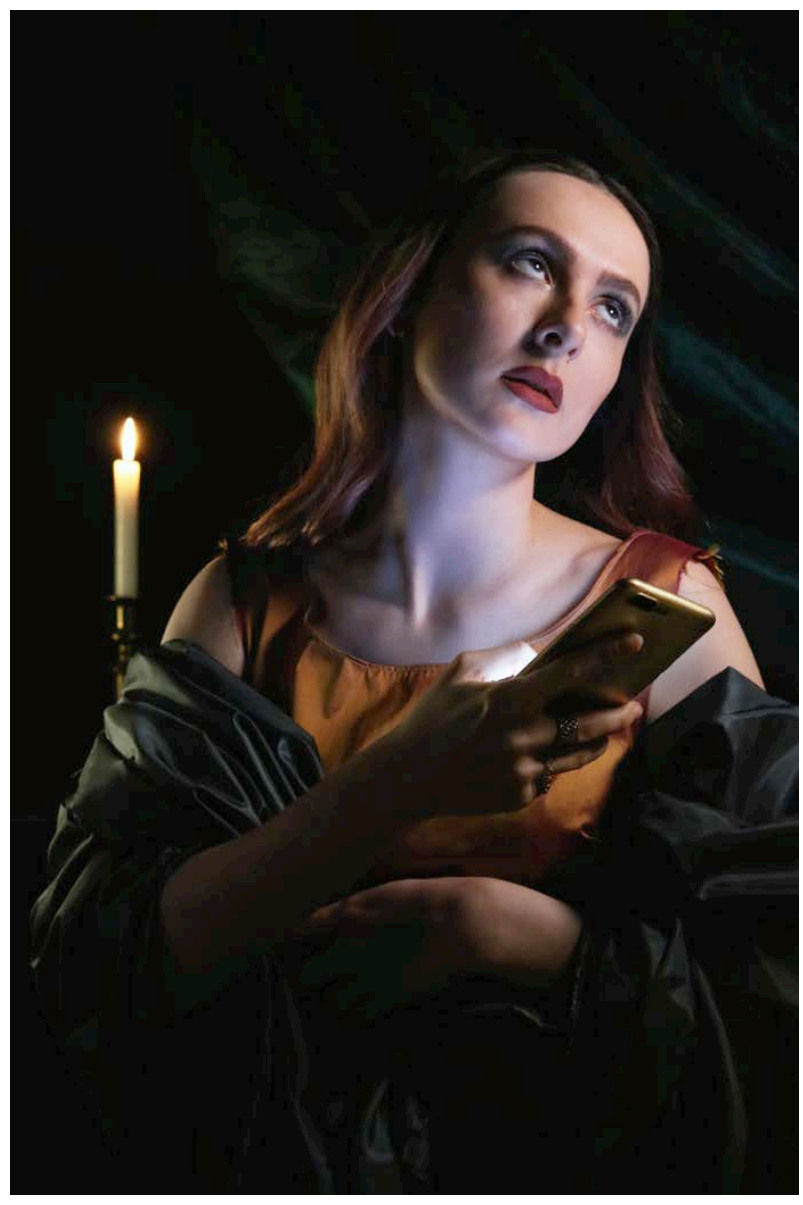

Figure 3.2: The Allegory of Patience, digital photo 2020.

Since then, there is very little for us to relate to one another over. His homophobia pushes me away from him. Neither of us will be open about our feelings. However - that poster has been on the wall of every bedroom I have ever lived in.

In studying those paintings with my father I understood that artists were able to capture cinematic moments that illustrated narrative tension and weight. I noticed that the complex expressions and poses provided cinematic suspense for both the subject and the viewer to experience simultaneously.

It wasn't until my adult life as a gay man that I started to notice how these comparisons between the subject and spectator appeared outside the galleries of my childhood. I noticed in the gay male community an obsession with binary forms of idealised feminine beauty and conventionalised heterosexual masculinity. Likewise even the online world platforms like Instagram, Google, Tinder and Hinge create hierarchies of images in their algorithms to prioritise beautiful objects. People and possessions appear consistently on the screen, all candidly performing like the paintings of my childhood. 


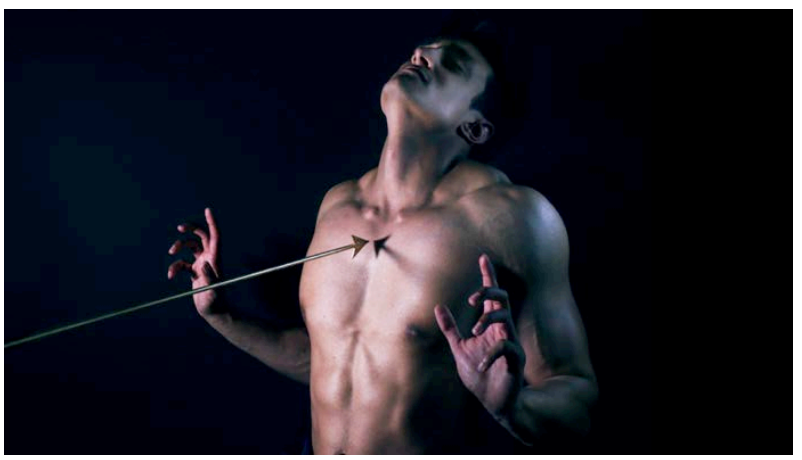

Figure 3.3 The Awakening, digital photo 2019.

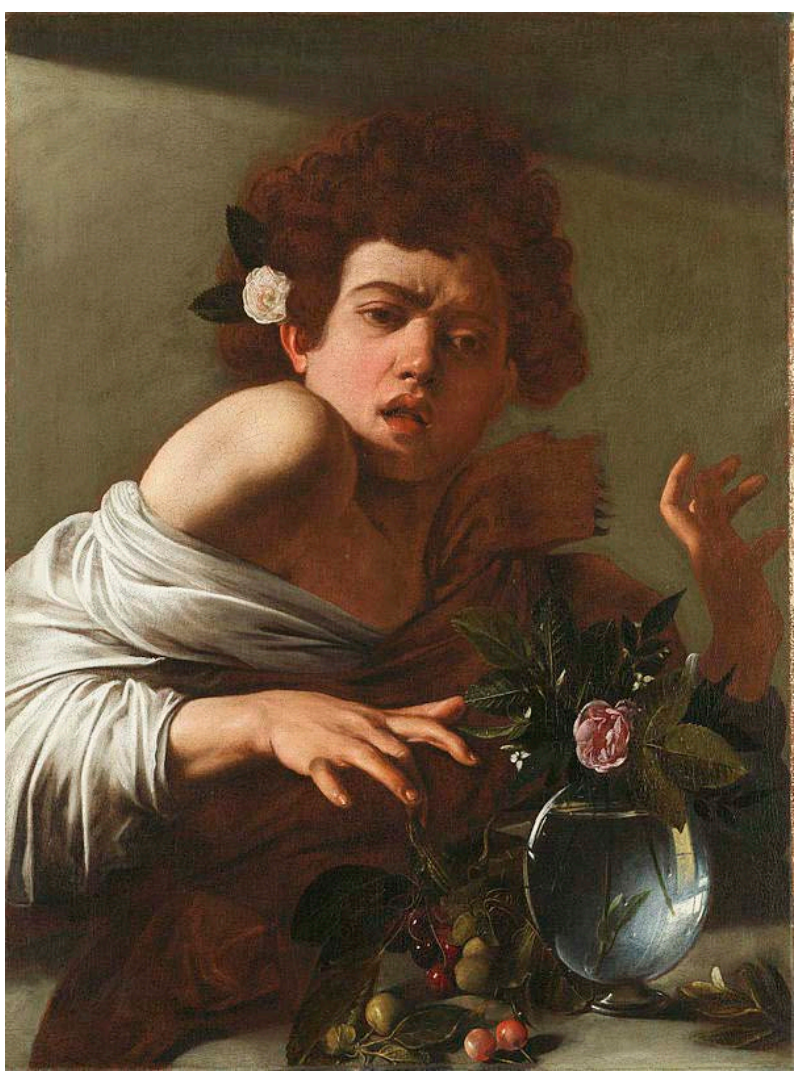

Figure 3.4: Boy Bitten By a Lizard by Michelangelo Merisi da Caravaggio, oil on canvas 1593/94.

I found over time my consumption of these images, began to warp my aesthetic and identity. I grew to be ashamed of my own 'lack' in aesthetic, queerness and conventional beauty. Why did these images of aesthetic beauty have such power over us? Who were they performing for? Was it like Mulvey had written about in her essay 'The Male Gaze', that these images and people performed for a male heterosexual audience? Why were these images being perpetuated and reproduced constantly?

While navigating these queer spaces, both in the online and real world, I began to create, collage, emulate, starting with the paintings of my childhood. I invited my friends and loved ones to perform and pose for me in shoots and short films, interpolating their narratives with personal experiences and postmodern ideas, as a way to situate my practice - not only as an artist but also as a queer person. These identities are intrinsically linked to one another, and their positions are constantly shifting and changing over time.

So where does Caravaggio's Boy Bitten by a Lizard fit in relation to all of this? Over my time exploring art galleries and museums with my father, I have to admit I never had much fondness for Caravaggio's 'Boy Bitten by a Lizard', despite remembering it vividly. I felt a sense of unease and awkwardness looking at him. The small figure hunches over the table inelegantly, with his red tragicomic expression staring out from within the small frame of the painting. 'Lizard' to me didn't have the innate beauty of 'The Birth of Venus' or Michelangelo's

'David' with their immense grand size and idealised forms commanding you to look.

It is only in my adult life when revisiting Caravaggio's 'Boy Bitten by a Lizard', that I understand why I felt so uneasy. In my research I started to find it a compelling painting for a number of reasons, it appears to be a painting largely under-appreciated in comparison to his other works.

Firstly 'Lizard' (as I will be nicknaming it from now on) was painted very early on in Caravaggio's career in 1593 or 94 when he moved to Rome in his early twenties. This was painted alongside a couple of other paintings such as 'Boy with a Basket of Fruit' or 'Bacchus', to be sold on the art market quickly. The painting represents the young form of the god Bacchus - god of wine, fertility and frenzied chaos. The image captures the moment Bacchus reaches into a garland of fruits and is unknowingly bitten by a lizard hiding amongst its leaves. Because of the extremely exaggerated, 'effeminate' pose the subject has in response to the small lizard bite, it is understood that this was one of Caravaggio's formative works to explore the 'drama' that he would be renown for later on in his artistic career.

A subject that comes up when talking about this image is the true identity of the model. There is some evidence to believe that it is Mario Minniti, Caravaggio's close friend and studio assistant, who has been identified in numerous other works. Others have theorised that the model is in fact Caravaggio himself. Caravaggio has been identified in other paintings such as 'Bacchus', and 'Medusa' to name a few. Evidence that builds upon this is the position of the model's hands, which references the way that Caravaggio would have held his palette and paint-brush. Considering that Caravaggio painted exclusively from life, he may have painted himself and reinterpreted his position 
into the context of 'Lizard'. Despite much discussion there still is not an entirely concrete answer to either.

I have decided that for my next photograph I will stage Caravaggio's Boy Bitten by a Lizard, but rather than having a model to project my work onto, I will shoot myself wirelessly as Bacchus. Since researching 'Lizard' I have a new found love and connection with it. My initial prejudice to it was an internalised one. My unease from looking at it was a projection of my unease looking at myself, and my current position at the time.

I mistakenly believed that my position as an image maker/photographer was that of an invisible passive spectator. Which is not true - the photographer themselves possess the same parts as the subject, even if they exist outside the traditional frame. The subjects in these images do not subject, even if they exist outside the traditional frame. The subjects in these images don't perform to a certain consistent gender or set of individuals but to the camera itself. The camera is the object we transfer our desires onto. Like Narcissus gazing longingly into his reflection, we perform to the camera and screen, which its technologies and sensors record indiscriminately, and are sent back to us in aesthetic shapes and lights on the screen. Lacan expanded this further in his writing of the Other where the subject requires validation by the gaze of the Other in order for traditional relationships to make sense.

To emphasise the power that the camera has I have chosen to enhance the original context by adding a mirror in the background of my staging of 'Lizard', as a reference images like Velázquez's painting 'Las Meninas'. In that image the mirror depicts the King and Queen of Spain looking into the scene in the position that the viewer would take looking into the painting.

Rather than have a King and Queen looking over their servants performing their duties, using a mirror to capture the camera independently recording the image without the photographer, illuminates the true power of the camera. Likewise situating it where the viewer would stand when they view the image, illuminates the look, not only as an individual practice but as a systemic infrastructure.
By performing as Caravaggio/Minniti, as Bacchus, I take the role of both model and artist, with the aim of expanding the position of the photographers look and gaze, challenging the notions of established rules of aesthetics. Existing in the image as both the subject and spectator, or even to put it in queer terms top and bottom non conforms to a binary position. It is my feeling that this is the position of my practice as an artist/ queer person. To embrace my own camp queerness within the context of this image, transforming my internalised shame into pride, becoming a part of the lexicon of human bodies, that are both looking, and are looked at.

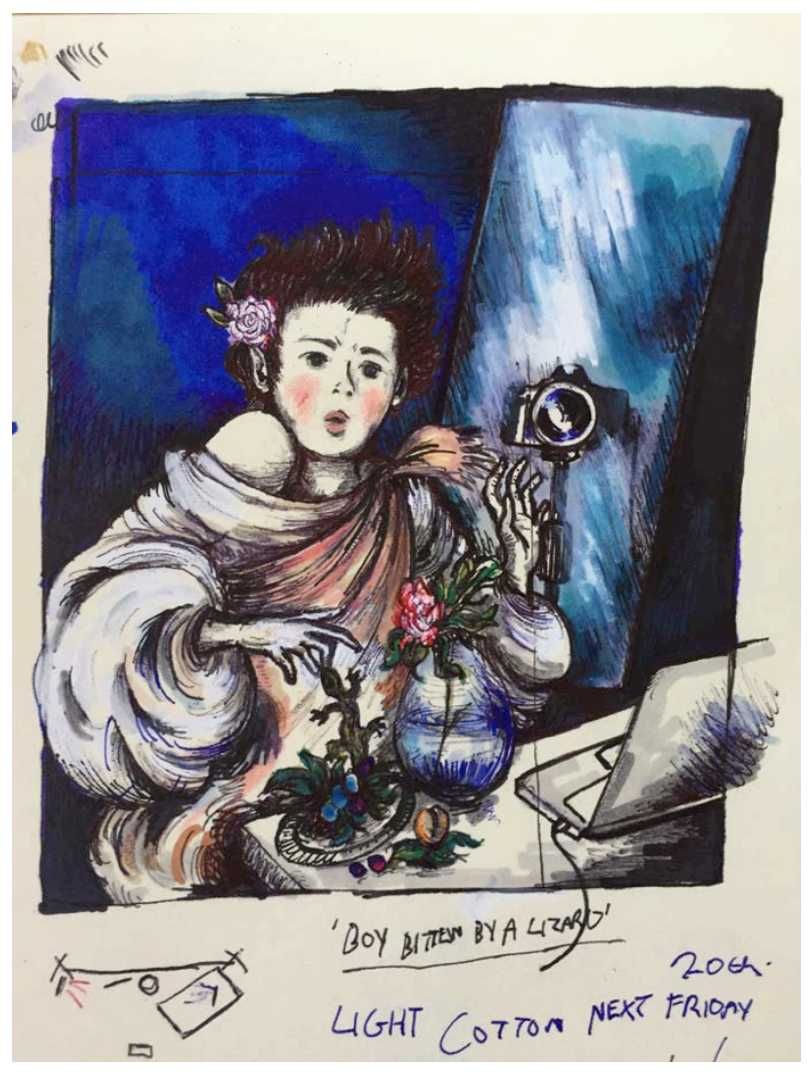

Figure 3.5 Concept Sketch for 'Boy Bitten By a Lizard' photograph. Pen and Ink 2020. 


\section{UNTRIED REALITIES: EXPERIMENTING WITH RECONSTRUCTED MEMORY}

\section{Zula Rabikowska, London College of Communication}

\subsection{Introduction}

This paper explores the relationship between identity, memory and belonging through a personal lens. I was born in Poland and at the age of 10 moved to the UK, and my life has been underpinned by reconciling my Polish and British identity, language and culture.

I want to explore the inconsistencies of memory and my connection with the familiar, yet strange, landscape where I grew up. Acknowledging migration as a journey and space of both trauma and transformation, Untried Realities proposes to open up different ways of understanding the immigrant experience. In this project, I want to unsettle the accepted notions of what characterises the idea of "home", and the boundary between imagined and lived experiences. I will be looking at memory as an unstable, fluctuating process, which contributes to our understanding of "self" and "identity".

\subsection{Untried realities}

In Poland and the UK, I feel as if I occupy an "inbetween" space, belonging neither here nor there, unable to feel truly at home anywhere. For Untried Realities I will return to the small village in Poland where I was born and grew up to create a series of fictional moments and scenes, which will be reconstructed from memory.

I will photograph objects and places linked to my childhood and couple these with a series of selfportraits. I've been inspired by the magic realism in Alma Hasser's photography and will develop my own methodology by reinserting myself to scenarios and landscapes and create images where I am partially obscured, or not fully present. I will use mundane household scenes to create an "untried reality," a life that never existed. I want to examine the barrier between the "real" and the "imaginary" and my own role within the Polish culture and landscape. Visiting Poland after having lived in the UK is a challenging and draining process. I am regularly reminded by my family, and occasionally strangers, of my unusual choices of vocabulary in Polish, insufficient knowledge of social etiquette in Poland, which sometimes lands me in unfavourable situations, or that the way I dress is not in tune with Polish expectations. When I visit Poland, I am therefore perpetually reminded that I do not fit socially, linguistically or physically.
The process of physically being in the landscape and visiting sites of childhood memory, which over the years have accumulated to form my understanding and relationship with Poland, is vital in the project. It is snippets of these memories that have created my "Polish identity", which contributes to my "otherness" as an immigrant living in Britain. The continuous sense of disjuncture underpins my relationship with the world around me. In Untried Realities, I will be using different postures, which will place my body and limbs into awkward positions, places or furniture, to replicate this feeling awkwardness and sense of loss.

\subsection{Methodology}

I will combine photography with multimedia elements to challenge the linear approach towards time and memory. I will use black and white film and develop the photos in the water from a Polish river to incorporate the physicality of the landscape directly into the photos.

I've also been influenced by Luke Willis Thompson's cinematic film portraits and will use this methodology to record moving portraits of myself in reconstructed scenarios. These moving portraits will seem still as first glance, and only upon closer inspection they will allow partial movement, such as undulating wind, or clock handles ticking (for example). They will accompany the black and white images and together create a more disrupted, non-linear approach towards memory. These different elements in the project will help me understand my relationship with the country where I was born and examine the idea of "home."

\subsection{Sound}

In this project I will be using visual as well as audio elements to re-create a set of "Untried Realities." For this purpose, my aim is to record two types of sound; first ambient sound to accompany the moving portraits, and second the sound of common swifts. Swifts are migratory birds and are known for being able to remain in flight without stopping. These birds spend most of their lives in flight, essentially never touching the ground, making them the perfect migratory birds, extremely adapted to doing everything while flying. (Letnik et al. 2007) Between May and September common swifts migrate to Eastern and Central Europe and as a child growing up in Poland, I remember every summer the sky being filled with swifts soaring across the horizon. Their shape and very distinct sound, which they produce mainly at sunset, for me is like Proust's Madeleine, instantly transporting me back to a time when I lived in Poland. 
The common swift will work on two levels, first as an overarching symbol of unresolved and going on migration, as second of all as sound piece that will link the series of "Untried Realities" through sound. For this project, I will record the sound of common swifts at sunset and incorporate this into the moving portraits that I create of myself.

\subsection{Experimenting and testing}

In preparation for the project, I created a sequence of images in my flat in London, where I also probe the boundaries between fiction and reality. Initially inspired by the outbreak of the Coronavirus, I place myself in various parts of the flat to visually bear the feeling of physical as well as emotional isolation, loneliness and longing for the outside world. This sequence was shot digitally, but helped me to visualise the composition of the portraits I will be creating for "Untried Realities".

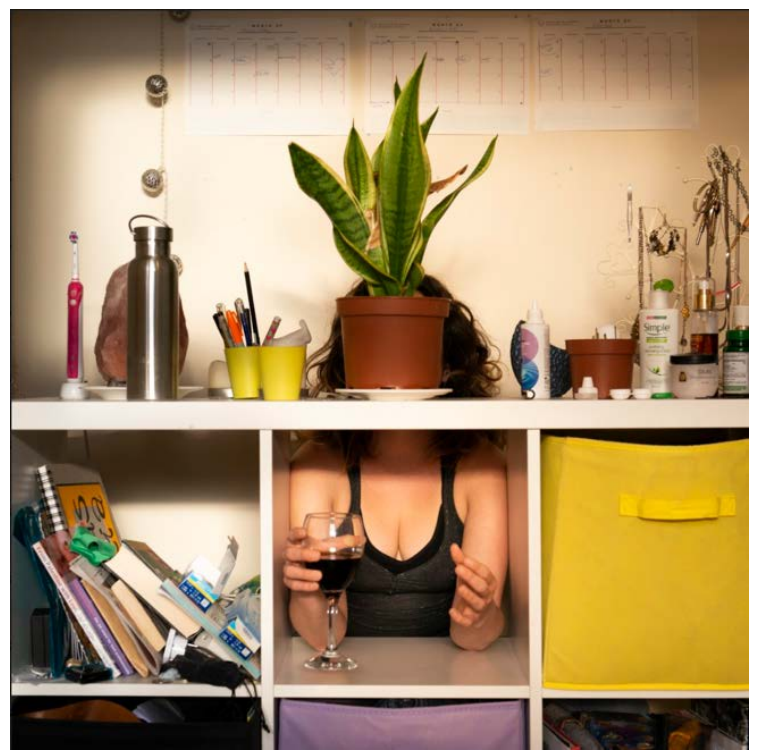

Figure 4.1: Untried Realities Experiment 1.

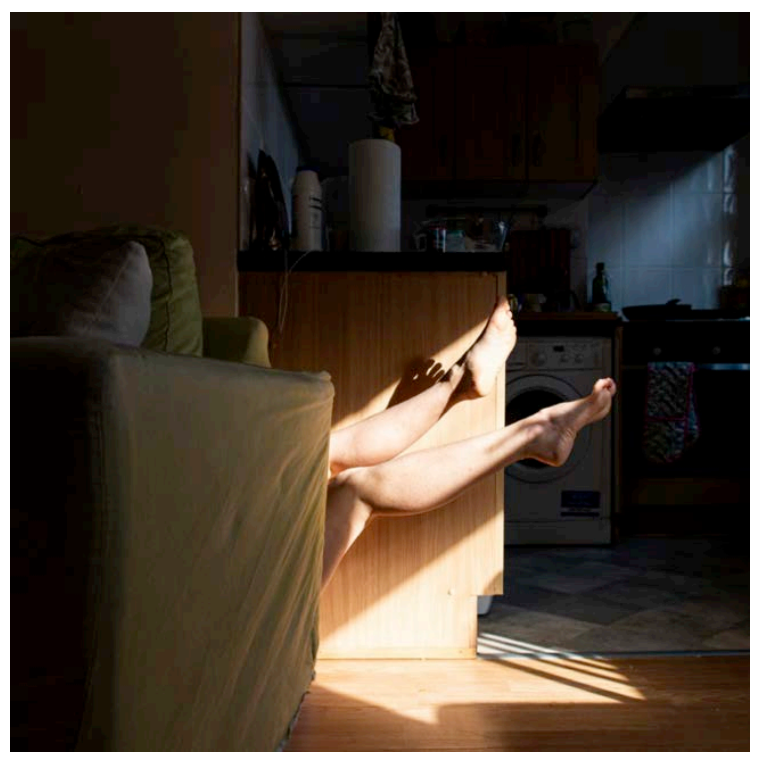

Figure 4.3: Untried Realities Experiment 3.

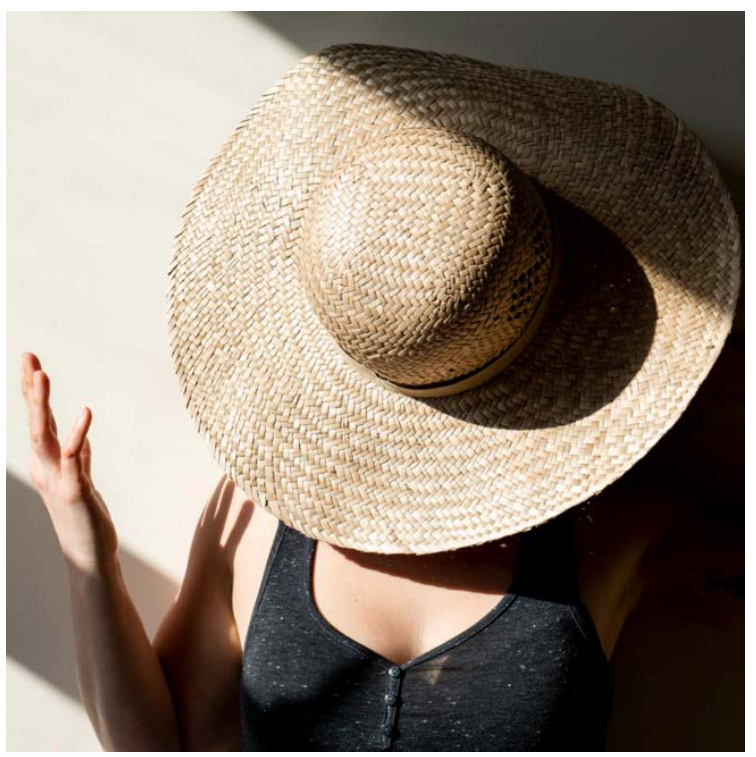

Figure 4.2: Untried Realities Experiment 2.

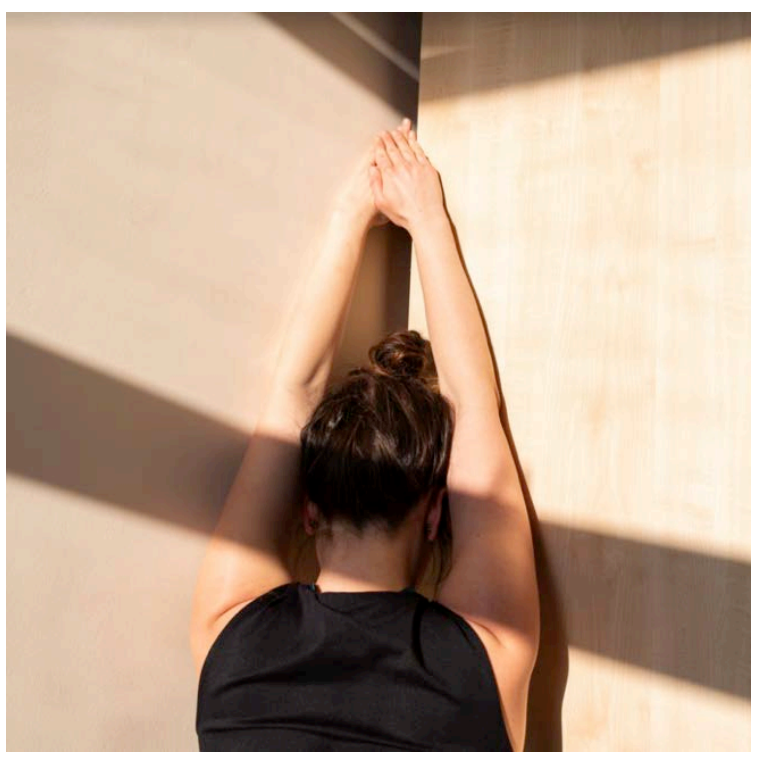

Figure 4.4: Untried Realities Experiment 4. 


\section{EMEVADA: GENESIS}

\section{Ruby Rossini, Fresh Britain}

\subsection{Introduction}

Emevada is a series of work, which aims to interrogate the viewer's perception of reading images through gender bias in contemporary culture. Emevada is a genderless fictional character who may "acquire" specific gender connotations based on the pose. The character's name is an anagram of Adam and Eve; who can be considered in many ways the originals from which the notion of gender was born in western society. This choice I pose as a provocation where Emevada becomes a symbol of a new genesis. Furthermore, the work is a response to Judith Butler's analysis of gender as performance. The character in this instance literally performs the notion of gender through various poses. Everything else commonly used to express gender is intentionally removed, leaving only the bare skin visible. In creating an ambivalent body gender can no longer be perceived as fixed, and Emevada can in some instances be read as male or female depending on the adopted pose or posture. The body is understood through behaviour alone, its physical form unchanged.

In the video installation, the character is performing a walk into a supposedly unknown environment. This ultimately symbolises the genesis of Emevada. The sound confirms the palpable tension of expectation itself - Emevada is born. The format is consciously left open for interpretation, to not force ideologies on the viewer. Yet through the absence of a gendered narrative, the viewer is purposefully left disoriented and unable to process an image with this lack, and with the apparent need, to place the figure through gender once more.

\subsection{Emevada}

The character was developed after an encounter with a 3D software provoked the question of how gender happened to be systematically ingrained in the software itself. Rubens (2016) asserts that our systems are not perfect because they are fed by an imperfect entity. This imperfection or bias can be present in any system; including tools such as software or algorithms, the development of which is fed by personal, social, and cultural positions; our human bias (Rubens 2016). Arguably as a result, questioning the construction of everything becomes fundamental.

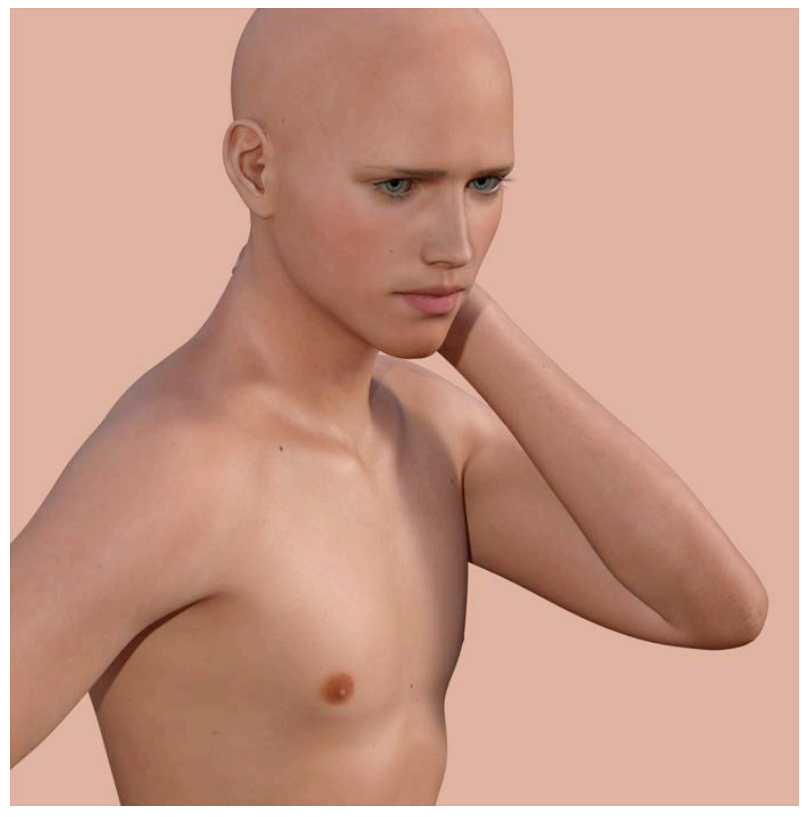

Figure 5.1: Emevada 1.

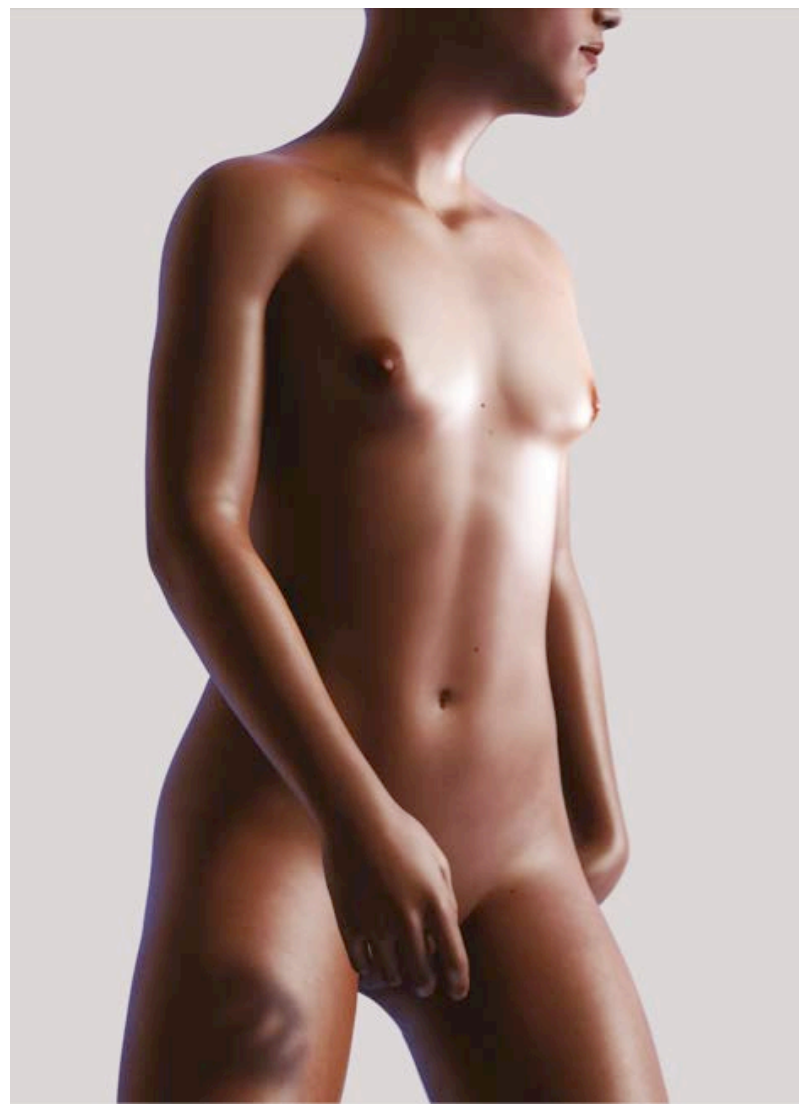

Figure 5.2: Emevada 2.

\subsection{DAZ 3D software}

Tools exist with the aim to perform a function and arguably they should not inherently come politically pre-imposed. Yet within the realm of Daz 3D this emerged as the case, and the modus operandi of the software appeared to be actively problematic. Depictions of gender generated by the software 
reflected a stereotypical and conservative narrative which sexualised women and depicted men as dominant.

This invited a deeper reflection as to why the 3D field so naturally invites this enquiry; in which the body is constructed from scratch to emulate reality. For example, in the software Daz 3D this begins through the construction of the default body, which follows mainstream ideas of beauty; physically fit for the male, slender and curvy for the female, with make-up present by default. Further, gender is 'visualised' in the characters' behaviour through the use of postures. Both characters come with a set of equivalent poses, identical in function, however not in form. The female poses were easily read as highly sexualised, and passive in nature; while the male poses expressed confidence and decisiveness in posture.

\subsection{The perception of gender}

The perception of gender in behaviour however, invites a different conversation; one in which gender is not inherent in the body, but is socially constructed and emulated. As the software's primary vehicle of assigning gender is rooted in posture, behaviour becomes the element through which gender is understood. Jean Baudrillard, speaks of hyper-reality as a model of reality, and "the generation by models of a real without origin or reality" (1994, p.1). Baudrillard refers to this as simulacrum. Judith Butler's (1999) theory of gender embraces the theory of simulacrum and argues that gender is a performative notion for which there is no original; it is rather, a behaviour carried out in society to gain intelligibility.

I would like to argue that through this lens, Daz 3D perpetuates an imitation of seemingly original notions of gender, yet in doing so creates the imitation itself. Gender as a constructed reality poses questions of a creator. I would like to assert, that the ways in which the female body has been historically sexualised suggest a male creator.

John Berger (1972) evidences this through his analysis of the origins of nude paintings of the female form. And further, Rubens (2016) explains the historical context in which only men were collectors, female nudes were highly desired for personal enjoyment, thus explaining the passive and seductive poses stereotypically associated with female depiction.

\subsection{Prejudged observations}

A later observation relating to the video installation itself, I would like to argue perhaps affirms how nudity itself, as historically and commonly associated with female figures, lends itself for the subject to be perceived as more feminine than masculine. While the video installation was exhibited at the London College of Communication, I recorded that most viewers when pressed to associate the figure with a gender, perceived Emevada as feminine. Interestingly, Emevada is born out of a male base mesh, even though the body has been modified to confuse and merge bodily aspects of both genders. I posit that it is perhaps the nudity of the figure which poses a trap in categorising its gender. Very unlike depictions of men, indeed, we are historically accustomed to witness female nudity and therefore it's association with both seduction and vulnerability. So perhaps again making judgements through a biased lens; one which is seemingly increasingly difficult to escape.

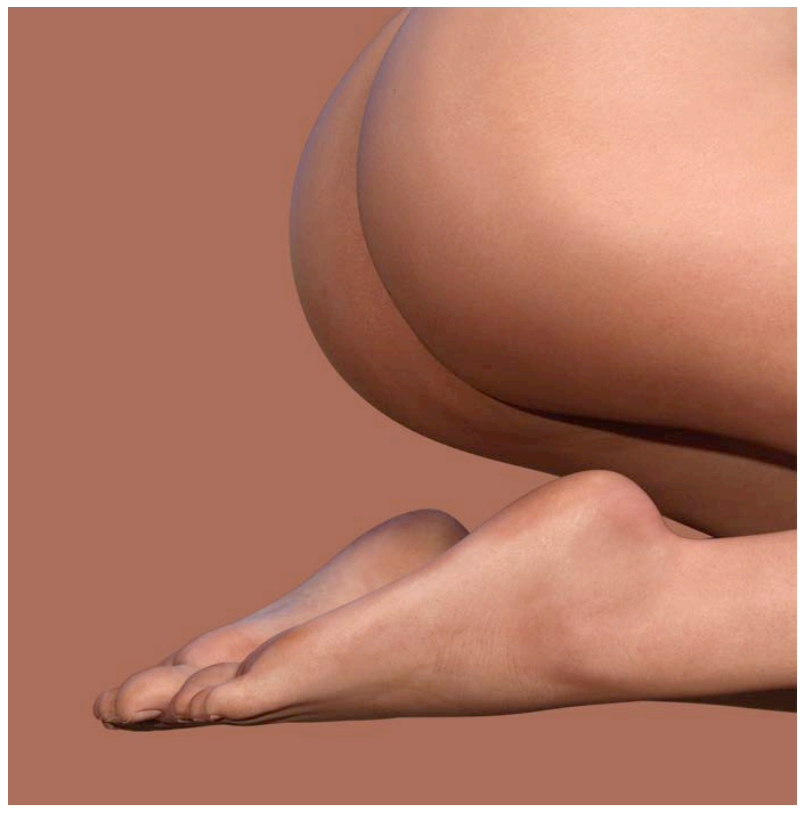

Figure 5.3: Emevada 3.

\subsection{Conclusion}

Ultimately, Emevada is intended to exist as a provocation, and does not wish to speak of one truth. Through this work I only wish to prompt conversation, and reveal the supposed truth hidden in our societal and cultural systems. Gender is an often polarised topic of discussion which so readily begins and ends its discourse with the body; a monumental and fixed entity in which all of our behaviours are explained, and thus eternally cast. Yet, if we diverge such discourse towards gender as a behaviour itself - not inherent to our body but instead ascribed onto it - a more sincere conversation can perhaps take place. 


\section{REFERENCES}

Albers, J. (2013) Interaction of Color. Yale University Press.

Baudrillard, J. (1994) Simulacra and Simulation. University of Michigan Press.

Berger, J. (1972) Ways of Seeing. London; British Broadcasting Corporation and Penguin Books.

Bullock, J. and Di Donato, B. (2016) Approaches to visualising the spatial position of 'sound-objects'. In Proc. of the Conference on Electronic Visualisation and the Arts, EVA 2016, pages 15-22, London, UK.

Butler, J. (1999) Gender Trouble. Routledge. New York.

Butler, J. (2009) Imitation and Gender Insubordination. Cultural Theory and Popular.

Di Donato, B., and Bullock, J. (2015) "gSPAT: Live Sound Spatialisation Using Gestural Control." In: Proceedings of Student ThinkThank at the $21^{\text {st }}$ International Conference on Auditory Display (ICAD 2015 STT), 7-8. Graz.

Di Donato, B., Dewey, C. and Michailidis, T. (forthcoming) Human-Sound Interaction, International Proceedings of the International Conference on New Interfaces for Musical
Expression, NIME 2020, Birmingham City University, Birmingham, United Kingdom.

Dourish, P. (2001) Where The Action Is: The Foundations of Embodied Interaction. MIT Press.

Gibson, J. J. (1966) The senses considered as perceptual systems. Houghton Mifflin.

Gibson, J. J. (1977) The Theory of Affordances. Hilldale, USA, 1:2.

Gibson, J. J. (1979) The Ecological Approach to Visual Perception. Boston: Houghton Mifflin.

Grandhi, S. A., Joue, G., and Mittelberg, I. (2011) Understanding naturalness and intuitiveness in gesture production. In Proceedings of the SIGCHI Conference on Human Factors in Computing Systems, CHI, pp.821-824, Vancouver, BC, Canada.

Katrine Lindvig (2017) Creating Interdisciplinarity within Monodisciplinary Structures. Ph.D. Dissertation. Faculty of Science, University of Copenhagen, Copenhagen, Denmark. Nr. 52/2018.

Pater, R. (2016) The Politics of Design: A (Not so) Global Design Manual for Visual Communication. Bis Publishers. 